\title{
Relato final do IV Encontro do \\ Fórum Nacional de Cursos de Geologia
}

\author{
Araxá (MG), outubro de 2004
}

\author{
Celso Dal Ré Carneiro \\ Universidade de Estadual de Campinas \\ José Fernando Pina Assis \\ Universidade Federal do Pará
}

* Este documento deve ser referido como segue:

Carneiro C.D.R., Assis J.F.P. 2006. Relato Final do IV Encontro do Fórum Nacional de Cursos de Geologia. Araxá (MG), 21 de outubro de 2004. Terræ Didatica, 2(1):86-90. $<$ http://www.ige.unicamp.br/ terraedidatica/ $>$.

Documento-base inédito: Carneiro C.D.R., Assis J.F.P. 2005. Sintese das contribuições do IV Encontro do Fórum Nacional de Cursos de Geologia. Araxá (MG),

21.10.2004. Campinas, julho de 2005. 6p.).

\section{Pauta}

Pauta aprovada na abertura da reunião do Fórum Nacional de Cursos de Geologia em Araxá, 21.10.2004:

1. Estágios de campo no Centro de Geologia Eschwege;

2. Financiamento de trabalhos de campo;

3. Disciplina de Geologia no Ensino Médio;

4. Política de cotas nas universidades;

5. Intercâmbio interinstitucional;

6. Reformas curriculares recentes;

7. Eleição da diretoria;

8. Preparação do V Encontro (Cuiabá - MT);

9. Indicação do local do VI Encontro.

\section{Introdução}

O Fórum Nacional de Cursos de Geologia realizou encontro, durante o XLII Congresso Brasileiro de Geologia, no dia 21 de outubro de 2004, na cidade de Araxá (MG), na sala Turmalina do Grande Hotel de Araxá. O evento, promovido pela Sociedade Brasileira de Geologia, incluiu a reunião em seu programa, sob a designação Fórum Nacional Ensino de Graduação em Geologia.

Estiveram presentes 17 (dezessete) dos 20 (vinte) cursos brasileiros de Geologia, Engenharia Geológica e Licenciatura em Geociências e Educação Ambiental, representados pelos respectivos coordenadores de cursos, vicecoordenadores ou representantes por eles indicados. Durante esse dia de 
reunião discutiram-se temas de grande interesse para os cursos de Geologia, cujos resultados estão sintetizados neste relato, elaborado sob responsabilidade exclusiva dos relatores. O documento reúne propostas, recomendações, decisões e temas identificados para a reunião de maio-junho de 2005.

A abertura da reunião ocorreu logo após a confirmação de quórum, estando presentes os professores Alexis Rosa Nummer (UFRuralRJ), Beatriz P. Duarte (UERJ), Cândido Moura (UFPA), Celso Dal Ré Carneiro (Unicamp), Claudio Migliotti (UFAM), Edi Mendes Guimarães (UnB), Eduardo Zaine (UNESP), Elvo Fassbinder (UFPR), Gorki Mariano (UFPE), Ismar de Souza Carvalho (UFRJ), Luiz Guilherme Knauer (UFMG), Márcia Elisa Boscatto Gomes (UFRGS), Messias Gilmar de Menezes (UFOP), Paulo Cesar Boggiani (USP - 2 cursos), Ricardo K. Weska (UFMT), Vanildo Pereira da Fonseca (UFRN), além do acadêmico Felipe Mattos Tavares (UFRJ), que representa os membros do movimento estudantil denominado Pró-ENEGE.

\section{Estágios de campo no Centro de Geologia Eschwege}

O presidente da Sociedade Brasileira de Geologia, prof. Rômulo Machado, abriu os trabalhos e relatou os antecedentes da discussão sobre o Centro de Geologia Eschwege. Assinalou sua avaliação de que o CGE não devesse ficar vinculado à CPRM, em virtude das variações sazonais de governo, que podem fazer oscilar a intensidade de apoio que o centro poderia receber do serviço geológico nacional. Sua proposta é a de perenizar o CGE, mediante a reativação do comitê gestor.

Nesse aspecto o prof. Rômulo recebeu apoio de vários presentes, como os profs. Messias Menezes e A.C. Correia Neves; este último assinalou que na reunião apresentará seus pontos de vista pessoais, lamentando a ausência de representantes da UFMG no encontro ${ }^{1}$. O prof. Messias destacou que se deve explorar mais esse novo conceito de uma casa multidisciplinar de ensino-aprendizagem, que se vem adotando para o CGE. O prof. Cândido destacou que a UFMG não precisa custear os trabalhos de campo de outras escolas; entende que este assunto está relacionado com o ponto seguinte das discussões desse dia, o do financiamento dos trabalhos de campo. O prof. Ismar admite que possa ser entendido pelos docentes da UFMG que a existência do conselho gestor seja uma ingerência sobre os docentes do IGc e da UFMG. Recomenda, por outro lado, que seja ampliada a abrangência do CGE, mediante a matrícula de alunos de outras IES, que seriam orientados por docente(s) de outras IES que houvessem proposto determinada(s) disciplina(s). O prof. Messias sugere que o conselho gestor seja composto por representantes da UFMG, SBG e CPRM, caso esta venha a apoiar o CGE.

A profa. Edi recomenda que não seja amarrada na proposta ao MEC a ênfase ou exclusividade do mapeamento geológico, nas ações do CGE, pois ele constitui uma contribuição essencial para a formação do geólogo brasileiro, que vai muito além do mapeamento geológico.

Decidiu-se recomendar que o Fórum Nacional de Cursos de Geologia apóie o documento elaborado por alunos de geologia de todo o país e que será entregue ao MEC em audiência com o Ministro, defendendo a continuidade do Centro de Geologia Eschwege e destacando sua importância central para a formação do geólogo brasileiro. Sugeriu-se também levar a questão à Comissão de Educação da Câmara e solicitar apoios da SBG, Petrobras e ANP.

Assinalou-se a necessidade de existirem pelo menos um ou dois professores residentes em Diamantina e que o CGE devesse assumir uma função ainda mais ampla do que somente as atividades de mapeamento geológico. Destacou-se ainda que a gestão colegiada, a ser implantada por meio da criação/reativação do conselho gestor, seja considerada uma ampliação da alternativa atual, mediante a possibilidade de intercâmbio de alunos nos moldes enunciados pelo prof. Ismar, ou seja, pela matrícula de alunos de outras IES, que seriam orientados por docente(s) de outras IES proponentes de determinada(s) disciplina(s).

\section{Financiamento de trabalhos de campo}

O item referente ao financiamento de trabalhos de campo foi aberto pelo prof. Celso, que indagou a cada coordenador presente informações sobre o custo estimado de manutenção por aluno no campo. Os dados acham-se listados na Tabela 1.

1 Nota dos relatores: Nesse momento, ainda não havia comparecido ao encontro o prof. Luiz Guilherme Knauer, como representante oficial da UFMG. 
Tabela 1 - Custo estimado por aluno no campo (2004)

\begin{tabular}{|c|c|c|c|}
\hline IES & Custo aluno/dila & IES & Custo aluno/dia \\
\hline JERJ & 30,00 & \multirow[t]{2}{*}{ UFRGS } & 15 a 30,00 \\
\hline IFAM & - & & 26,00 (em média) \\
\hline BA & 15 a 30,00 & UFRJ & 20,00 \\
\hline $\mathrm{CE}$ & - & UFRN & 25,00 \\
\hline JFMG & 9,00 & UFRuralRJ & 10,00 \\
\hline IFM & 12,50 & UnB & 25,00 \\
\hline FOP & 28,00 & UNESP & - \\
\hline FPA & 30,00 & Unicamp & 28,00 \\
\hline FPE & - & Unisinos & - \\
\hline FPR & 33,00 & USP & 30,00 \\
\hline
\end{tabular}

Os resultados indicam que um valor médio para as despesas por aluno por dia de campo deverá oscilar atualmente entre $\mathrm{R} \$ 23,00$ e $\mathrm{R} \$ 24,00$.

Foi externada ainda a preocupação com a quantidade de aulas de campo nos cursos, permanecendo a recomendação de se continuar levantando dados de cada curso, e com a solicitação feita a todos os cursos para que reexaminem seus dados para saber se de fato vem sendo cumprida a recomendação do Fórum de que as atividades de campo atinjam $20 \%$ da carga horária total.

As manifestações dos coordenadores sobre o tema podem ser resumidas conforme segue:

- O prof. Cândido sugere que a luta seja, de início, interna, garantindo-se nos próprios projetos pedagógicos a relação de 4 alunos por professor; assinala que na UFPA essa relação nos trabalhos finais de curso atinge 6 alunos por docente.

- A UFRN assumiu desde o primeiro coordenador de curso o compromisso histórico com o trabalho de campo.

- Na UFOP o trabalho de campo é garantido em disciplinas específicas.

- $\quad \mathrm{Na}$ UFBA os alunos estão em greve há três meses, sendo uma de suas reivindicações o aumento na quantidade de trabalhos de campo e o oferecimento pela universidade de equipamentos em condições de uso. Foi proposto que o Fórum se envolvesse na defesa, junto à Reitoria, de mais recursos para trabalhos de campo na UFBA.
- Recomendou-se que o Fórum circulasse informações acerca de locais mais baratos para alojamento de alunos.

- Recomendou-se que o Fórum procurasse intercambiar informações acerca de seguros de vida e acidentes pessoais, para alunos e professores. A UFPR possui alguma experiência nesse sentido, que pode ser compartilhada.

- Sugeriu-se que o Fórum recomendasse que, durante trabalhos de campo, os grupos de alunos e seus professores procurassem fazer algum tipo de interação com a população das cidades visitadas.

Foi decidido recomendar aos cursos que fizessem constar nas ementas de disciplinas, bem como nos respectivos projetos pedagógicos de cada curso a questão do campo. Não houve unanimidade quanto à quantidade de horas computadas por dia como trabalhos de campo (6, 8 ou 10 horas?). Ficou decidido deixar a critério de cada IES tal definição. Uma pequena subcomissão foi organizada (profs. Elvo e Boggiani) com a finalidade de elaborar um documento que destacasse aos demais professores de cursos de Geologia a importância que se tem atribuído atualmente ao campo na formação do geólogo. O documento deveria indicar ainda que os recursos destinados aos trabalhos de campo não poderiam nem deveriam ser subordinados às regras adotadas pelo TCU, no caso das universidades federais.

\section{Disciplina de Geologia no Ensino Médio}

Os profs. Rômulo Machado e Cristina Toledo referiram a existência de documento que deverá ser levado ao conhecimento do MEC, com a finalidade de apresentar uma proposta formal para a inclusão de uma disciplina específica de Geologia no Ensino Médio. Convidaram os demais coordenadores interessados nessa proposição a se manifestar por meio de algum tipo de endosso formal de suas respectivas IES acerca da idéia. Informações acerca do documento básico deverão ser disponibilizadas pelos autores por e-mail e na Internet.

- Recomendou-se incluir os documentos mencionados e de interesse geral no sítio do Fórum, cuja URL é < http://www.ige.unicamp.br/ $\sim$ forum/arquivos/.

- O prof. Pedro Gonçalves sugeriu que houvesse uma reforma curricular que introduzisse tal 
disciplina no Ensino Básico. O prof. Cândido propõe que a denominação não se restrinja à Geologia, mas que deva abranger os conteúdos de Geociências, para dar mais visibilidade. Assinalou-se ainda que a iniciativa abriria horizontes até mesmo para a expansão do número de jovens que se interessam pelos cursos de Geologia.

- Os estudantes de Geologia solicitaram que se incluíssem os e-mails dos centros acadêmicos na lista de e-mails do Fórum, não existindo consenso a respeito.

- Decidiu-se que o Fórum deve apoiar a SBG e a USP na defesa de uma disciplina com os moldes acima discutidos [N.R.: embora não tenha havido consenso a respeito de qual o nível de escolaridade: fundamental ou médio? $\left.{ }^{2}\right]$ junto ao MEC. A proposta deve ser bem elaborada para se evitar confusão ou conflitos com a disciplina de Geografia.

- O embasamento da proposta no que se refere a Ciências da Natureza é composto de três aspectos:

1. Não se pode tratar de Ciências da Natureza eliminando $99 \%$ da massa ocupada pela própria Natureza;

2. A Geologia não pode ser dividida/disseminada em informações esparsas distribuídas em outras disciplinas;

3. A Geologia possui características independentes em relação a outras Ciências.

- No tocante a Ciências Ambientais, foi sugerido que se escrevesse um artigo específico, por meio de uma pequena subcomissão (profs. Edi Guimarães, Pedro, Cândido, Elvo, Celso e Vanildo) com a finalidade de elaborar a primeira minuta de idéias.

- O prof. Ricardo Weska levantou um tema para reflexão: quanto temos sido competentes na formação de futuros biólogos e outros profissionais que, afinal, serão os responsáveis por ministrar esses conteúdos a futuros alunos? Aponta que um caminho para melhorar esse panorama seria a designação dos melhores quadros docentes para ministrar tais disciplinas.

- O prof. Pedro indicou dois eixos para reflexão sobre a proposta SBG-USP:

2 N.R. $=$ Nota dos relatores.
- Necessidade do trabalho com Geologia como conteúdo importante na formação de cidadãos;

- Importância da participação dos geólogos no esforço de democratização do conhecimento.

- O prof. Pedro assinalou ainda a possibilidade de que os alunos colaborem nesse esforço.

\section{Política de cotas nas universidades}

Após alguns relatos e troca de informações acerca de recentes decisões do MEC sobre essa iniciativa do governo federal, imposto às universidades, os presentes aprovaram a seguinte decisão:

- O Fórum discorda do uso político das cotas, agravado pela inclusão de desvantagens (desestímulos) para aquelas IES que não aceitarem participar do regime de cotas.

\section{Eleição da diretoria do Fórum Nacional de Cursos de Geologia}

Na reunião, com a presença de representantes formais de dez cursos, a nova Diretoria do Fórum foi eleita por aclamação, sendo composta pelos seguintes professores:

- José Fernando Pina Assis (UFPA) - presidente;

- Beatriz P. Duarte (UERJ) - vice-presidente;

- Ricardo K. Weska (UFMT) - coordenador do Encontro de Cuiabá, 2005.

\section{Local de realização do VI Encontro, em 2006}

Duas cidades foram apresentadas como candidatas a sediar o encontro do Fórum após o evento de Cuiabá, a saber: Natal, pelo prof. Vanildo (UFRN), e Rio de Janeiro pelos profs. Beatriz (UERJ) e Alexis (UFRRJ). Foram feitos relatos sobre vantagens e desvantagens de cada proposta, com ampla troca de informações. Em função da argumentação apresentada e das sugestões feitas pelos proponentes, indicou-se a cidade do Rio de Janeiro como sede da reunião de 2006, em esforço conjunto das três IES mantenedoras de cursos de Geologia: UERJ, UFRJ e UFRRJ. A decisão deverá ser referendada no Encontro de Cuiabá. 
Ficou postergada a discussão do tema Intercâmbio interinstitucional, assim como o da criação do CON$G E O$, em função de não haver tempo para que ambos fôssem adequadamente discutidos. Dessa forma, os assuntos do intercâmbio de alunos entre uma instituição e outra e a questão da inserção do profissional Geólogo no sistema CONFEA/CREAs ou a eventual criação do CONGEO ficaram adiados para a próxima reunião.

\section{Preparação do V Encontro}

\section{Local de realização: Cuiabá (MT)}

Considerando-se os itens de pauta que não puderam ser debatidos na reunião, os presentes aprovaram a seguinte pauta para a reunião de Cuiabá, tendo encarregado alguns colegas para que providenciassem a preparação dos temas:

\section{Intercâmbio interinstitucional}

O levantamento de dados e eventual palestra a respeito do intercâmbio ficará a cargo da profa. Márcia Boscato Gomes.

\section{Reformas curriculares recentes}

Para esse tema decidiu-se indicar o prof. Gorki Mariano como organizador.

\section{Financiamento de trabalhos de campo}

Para esse tema decidiu-se indicar os profs. Pina, Celso e Elvo como organizadores de uma coleta de dados sobre custos, inserção nos projetos pedagógicos e cargas horárias praticadas.

\section{Avaliação do Dia Nacional de Divulgação da Geologia, 30 de maio}

Para esse tema decidiu-se indicar a profa. Beatriz Duarte como relatora.

\section{Reforma Universitária}

Foram sugeridos os nomes dos profs. Dominguez (ANDES) e Matilde Kenje (Pró-Reitora de Graduação UFMT) como convidados para proferir palestras.

\section{6. Ênfases na formação de geólogos e conflitos}

Para esse tema decidiu-se indicar o prof. Vanildo como relator.

\section{Disciplinas básicas de Física, Química e Cálculo}

Para esse tema decidiu-se indicar o prof. Boggiani como relator.

\section{Presentes na reunião}

\section{Encontro do Fórum Nacional de Cursos de Geologia}

\section{Participantes na parte da manhã}

- Total de 42 presentes (incluídos 16 coordenadores)

\section{Participantes na parte da tarde}

- Total de 18 presentes (incluídos 10 coordenadores)

\section{Coordenadores de cursos}

- Alexis Rosa Nummer (UFRuralRJ)

- Beatriz P. Duarte (UERJ)

- Cândido Moura (UFPA)

- Celso Dal Ré Carneiro (Unicamp)

- Claudio Migliotti (UFAM)

- Edi Mendes Guimarães (UnB)

- Eduardo Zaine (UNESP)

- Elvo Fassbinder (UFPR)

- Gorki Mariano (UFPE)

- Ismar de Souza Carvalho (UFRJ)

- Luiz Guilherme Knauer (UFMG)

- Márcia Elisa Boscatto Gomes (UFRGS)

- Messias Gilmar de Menezes (UFOP)

- Paulo Cesar Boggiani (USP - 2 cursos)

- Ricardo K. Weska (UFMT)

- Vanildo Pereira da Fonseca (UFRN)

Representante discente

- Felipe Mattos Tavares (UFRJ). 